\title{
Searching for the Middle Zone of Chinese and American Mathematics Teaching through Math Camps
}

\author{
Zhiqiang Yuan \\ Hunan Normal University, China \\ Gabriel Matney \\ Bowling Green State University, U.S.A.
}

Two math camps were jointly carried out in two middle schools in a City in China by two groups of prospective mathematics teachers. One group of them consisted of 12 prospective teachers led by a mathematics teacher educator who came from a midwestern university in the U.S., and the other group of them consisted of 18 prospective teachers led by a mathematics teacher educator who came from a university in central China. The strengths and weaknesses of math camps from the perspective of Chinese and American prospective mathematics teachers were found by analyzing their reflection reports on math camps, which reflected their differences on teachers' noticing of classroom teaching. The results showed that the middle zone of Chinese and American mathematics teaching might include strengthening adherence to teaching both essential content and representational form.

Keywords: Chinese and American, prospective teachers, math camp, teacher noticing, middle zone.

In recent years, communication about teaching between Chinese and American mathematics teachers has become more and more frequent with the development of economy and society. There have been different types of communication between Chinese and American mathematics teachers.

Chinese and American mathematics teachers each conducting a lesson is one kind of typical communication. Following the lessons, they often discuss and comment on these lessons (Yuan \& Ricks, 2011). This type of communication provided some opportunities for learning from each other between Chinese and American mathematics teachers. However, this type of communication is often not sufficient and the effect of learning from one another is rather limited because of: (1) meeting for a short time, (2) lack of communication before and during the preparation for lessons, and (3) the existence of many barriers including language barriers during the discussion of lessons. Considering the limitations in the above-mentioned type of communication, 
we will introduce a new type of communication about teaching between Chinese and American mathematics teachers, namely jointly carrying out teaching activities between the two of them. Through this type of communication about teaching, they can get in touch with each other more sufficiently.

The purpose of this study was to make a contribution to searching for the middle zone of Chinese and American mathematics teaching by carrying out teaching activities through math camps. Specifically, two research questions were investigated in this study: (1) what are the strengths and weaknesses of classroom teaching in math camps? (2) What is the middle zone of Chinese and American mathematics teaching based on the prospective teachers' noticing of classroom teaching in math camps?

\section{Theoretical Framework}

\section{Middle Zone of Mathematics Teaching}

$\mathrm{Gu}$ Lingyuan who is a well-known Chinese mathematics educator proposed the following perspective in the 1999 International Conference on Mathematics Education between China and the U.S.: during the important period for searching for the middle zone between the East and West culture, searching for the middle zone is not only the big strategies of mathematics education reform, but also the big trend of the whole educational reform. Shulman who attended that conference also agreed with this perspective and suggested Chinese and American educators visiting the middle zone and searching for some basic ideas and conceptions. These can be done by some cross-culture comparisons and learning from each other (Gu, Yi, \& Nie, 2003). In the book The Middle Path in Math Instruction: Solutions for Improving Math Education, An (2004) revealed the current dilemmas in mathematics education in the U.S. and China, traced the philosophical and historical development of mathematics education in both countries, and pointed out that cultural factors greatly contribute to the teaching and learning of mathematics. Taking Teaching Geometric Probability as an example, Yuan and Ricks (2011) compared Chinese and American mathematics teachers' classroom teaching from the perspective of mathematical problems. They tried to know whether Chinese and American mathematics teachers have found the satisfied middle zone. The results showed that from the ways of presented problems and the strategies of solving problems, Chinese and American mathematics teachers seemed to take a step to learn from one another. However, they have still not learned their counterparts' quintessence. For example, using physical models for demonstration and small group learning are common teaching strategies used by American mathematics teachers, however, when the Chinese teachers used these strategies in Yuan and Ricks' study (2011), it became a mere formality. Similarly, teaching with variation was regarded as a commonly used teaching 
strategy by Chinese teachers (Huang \& Li, 2017), however, when American teacher used this strategy in Yuan and Ricks' study (2011), the challenge was reduced. Many other scholars, such as Jinfa Cai (Cai, 2005; Cai, Ding, \& Wang, 2014; Cai \& Wang, 2010), Rongjin Huang (Huang \& Cai, 2011; Huang, Barlow, \& Prince, 2016), Liping Ma (1999) and Meg Schleppenbach (Schleppenbach, Flevares, Sims, \& Perry, 2007; Schleppenbach, Perry, Miller, Sims, \& Fang, 2007), have done some comparative studies between Chinese and American mathematics teacher education and tried to find the features of Chinese and American mathematics teaching. It is supposed that both countries can learn from the others' strong points and close the gap. Then, they may find the satisfied middle zone. Lastly, studies on middle zone will improve the development levels of mathematics education for both countries. These efforts have certainly made an effect but have thus far not reached a general conclusion.

\section{Teachers' Noticing of Classroom Teaching}

Research on teachers' noticing in the United States from the 1980's to the early 2000's gave evidence that novice teachers' noticing was not as nuanced, correct, and rich as more experienced teachers (Berliner, 2001; Carter, Cushing, Sabers, Stein, \& Berliner, 1988; Sabers, Cushing, \& Berliner, 1991). From these early studies researchers' interest in teachers' noticing grew as a desire to explore the outcomes of improved teacher noticing grew (Santagata, 2011).

Teachers' noticing of classroom teaching has now become a prominent area of research in teacher education (Huang \& Li, 2012; Schack, Fisher, \& Wilhelm, 2017; Sherin \& Han, 2004; Sherin \& van Es, 2005; Sherin, Jacobs, \& Philipps, 2011; Star \& Strickland, 2008; van Es \& Sherin, 2008). Teachers' ability of noticing critical events is regarded as an important expertise of teachers. According to the Learning to Notice Framework, teachers' skill of noticing for teaching consists of three main aspects: (1) identifying what is important in a teaching situation; (2) using what one knows about the context to reason about a situation; and (3) making connections between specific events and broader principles of teaching and learning (van Es \& Sherin, 2008). Huang and $\mathrm{Li}$ (2012) examined 10 experts and 10 novice teachers' noticing of classroom events in China. They found both expert and novice teachers highly attended to developing students' mathematics knowledge coherently and developing students' mathematical thinking and ability. They also paid attention to students' self-exploratory learning, students' participation, and teachers' instructional skills.

\section{Method}

\section{Participants}

The participants consisted of 12 ( 2 males and 10 females) prospective 
mathematics teachers and a mathematics teacher educator (pseudonym: $D r . A$ ) from a midwestern university in the U. S. (pseudonym: American A University) and 18 (5 males and 13 females) prospective mathematics teachers and a mathematics teacher educator (pseudonym: $D r . B$ ) from a university in central China (pseudonym: Chinese B University).

The U.S. prospective teachers were all Caucasians and entered their teacher education program as freshmen in college. The twelve prospective mathematics teachers from the U.S. had varying levels of experiences in schools because of their length of time in their education program. There were five sophomores and three juniors who had visited multiple schools for short term observations of teaching and understanding school policy in the U.S. but had not yet taught in classrooms themselves. The four seniors had spent an additional five weeks working beside a classroom mentor teacher and taught a two-week unit to K-12 students during their mathematics methods course.

Chinese prospective mathematics teachers consisted of two different groups. Sixteen of them (4 males, 12 females) are senior undergraduate students. They had just finished their fieldwork classroom experience for eight weeks. Two of them ( 1 male, 1 female) were in their first year of graduate school. One female was Xinjiang Uighur and the others were all the Han nationality.

\section{Procedures}

On the morning of May 11, 2016, an American mathematics teacher educator, Dr. A, and three American prospective teachers visited the department of mathematics of Chinese B University. They talked about how to organize math camps jointly in the winter of 2016. From December 28, 2016 to January 5, 2017, an American mathematics teaching group consisted of 12 prospective teachers and a mathematics teacher educator (Dr. A) and a Chinese mathematics teaching group consisted of 18 prospective teachers and a mathematics teacher educator (Dr. B), jointly carried out two math camps for middle school students in China. During these teaching activities jointly carried out by Chinese and American prospective mathematics teachers, they experienced the following activities: (1) ice-breaking activities; (2) expert lecture; (3) math camp training; (4) China-US dialogue; (5) the first math camp; (6) the second math camp; (7) farewell party (See Table 1).

In what follows we give a more detailed account of the math camp at School B to provide the reader a view into the setting of the data collection.

At the beginning of the math camp, all middle school student campers were divided into six teams. Each team was named after a mathematician: Euler, Pascal, Archimedes, Gauss, Euclid or Pythagoras.

The headmaster of School B gave a brief introduction and officially opened the camp. Chinese and American prospective mathematics teachers accompanied by Dr. A collectively performed a math camp dance followed by teaching each team their own short and unique dance. The dance for the whole math camp named 2017 math camp was elaborately created by the American 
mathematics teaching group, which integrated many mathematical operations such as plus, minus, multiply, division and exponents. They also prepared a team dance for each team of math camp.

\section{Table 1}

\section{Schedule for Math Camps Jointly Carried Out by Chinese and American} Prospective Mathematics Teachers

\begin{tabular}{|c|c|c|}
\hline Date & Topic & Content \\
\hline $\begin{array}{l}\text { On the afternoon } \\
\text { of December } \\
28,2016 \\
\text { On the morning of } \\
\text { December } \\
29,2016\end{array}$ & $\begin{array}{l}\text { ice- } \\
\text { breaking } \\
\text { activities } \\
\text { expert } \\
\text { lecture }\end{array}$ & $\begin{array}{l}\text { Chinese and American mathematics teaching } \\
\text { groups met each other and participated in some ice- } \\
\text { breaking activities } \\
\text { American mathematics teacher educator, Dr. A, } \\
\text { gave a lecture with a title Impacts of Lesson Study } \\
\text { incorporating Open Approach on U.S. Teachers } \\
\text { Mathematics Knowledge for Teaching and Students } \\
\text { Mathematical Knowledge at the Yuelu Mountain } \\
\text { Mathematics Education Forum hosted by the } \\
\text { department of mathematics of Chinese B } \\
\text { University. More than } 100 \text { prospective teachers } \\
\text { attended the lecture. }\end{array}$ \\
\hline $\begin{array}{l}\text { In the afternoon of } \\
\text { December } 29 \text { and } \\
\text { in the morning and } \\
\text { afternoon of } \\
\text { December } \\
30,2016\end{array}$ & $\begin{array}{l}\text { math } \\
\text { camp } \\
\text { training }\end{array}$ & $\begin{array}{l}\text { American mathematics teaching group trained } \\
\text { Chinese mathematics teaching group on how to } \\
\text { organize math camps so that they can cooperate } \\
\text { effectively with each other in the middle school } \\
\text { math camps. }\end{array}$ \\
\hline $\begin{array}{l}\text { On the evening of } \\
\text { December } \\
30,2016\end{array}$ & $\begin{array}{l}\text { China-US } \\
\text { dialogue }\end{array}$ & $\begin{array}{l}\text { Chinese group leader (Dr. B) communicated } \\
\text { Chinese mathematics teaching with American } \\
\text { group leader (Dr. A). American prospective } \\
\text { mathematics teachers attended this meeting. }\end{array}$ \\
\hline January 3,2017 & $\begin{array}{l}\text { the first } \\
\text { math } \\
\text { camp }\end{array}$ & $\begin{array}{l}\text { Chinese and American prospective mathematics } \\
\text { teachers jointly carried out math camp for middle } \\
\text { school students in School A. }\end{array}$ \\
\hline January 4,2017 & $\begin{array}{l}\text { the second } \\
\text { math } \\
\text { camp }\end{array}$ & $\begin{array}{l}\text { Chinese and American prospective mathematics } \\
\text { teachers jointly carried out math camp for middle } \\
\text { school students in School B. }\end{array}$ \\
\hline January 5,2017 & $\begin{array}{l}\text { farewell } \\
\text { party }\end{array}$ & $\begin{array}{l}\text { Chinese and American prospective teachers } \\
\text { participated in farewell party. They exchanged gifts } \\
\text { for friendship. }\end{array}$ \\
\hline
\end{tabular}

Then, Chinese and American prospective mathematics teachers coorganized a series of activities, which included three main activities involving mathematical tasks: Brain Challenge, Math Stations and Math Relay. During the Brain Challenge activity, the campers of math camp tried to solve mathematical problems on the screen as a team. These mathematical problems involved the following activities: removing toothpicks to change the shape of figures; filling in the squares using the given numbers so that each equation is true; logical reasoning according to the given information; counting the times of a given number appearing in the page number. During the Math Stations 
activity, there were six math stations (water cups, go fish, math tag, number spelling game, magic cards, and brain train). Each math station had two station leaders. They were in charge of explaining rules for the game and evaluating performance of each team. The team leaders guided team members to pass these stations one after another. During the Math Relay activity, the campers of math camp competed to find the values of algebraic expressions as a team.

In the math camp, all scores were given to the team and not given to any individual person. There were two assessment systems in the math camp. One evaluated the abilities of each team to solve problems. Prospective teachers gave scores to the teams according to their degrees of finishing mathematical tasks. The strongest problem-solving team was selected. The second assessment was an evaluation of the spirit of team cooperation for each team. Prospective teachers gave the teams some paperclips as a reward when the team showed a spirit of good team cooperation. Each teams' paperclips were then linked together to make a long chain. By comparing the length of the chain made by paperclips, the best team for cooperation was selected. These activities played important roles for promoting communication about teaching between Chinese and American prospective mathematics teachers, exploring their noticing of classroom teaching, and searching for the middle zone of Chinese and American mathematics teaching.

\section{Instruments}

As a qualitative research study, the researchers themselves were the primary instruments. In addition, a reflection prompt and procedures were also used to collect prospective mathematics teachers' reflection on the whole activity of communication about teaching between the Chinese and American mathematics teachers. Seven aspects were included in this reflection prompt and procedures: (1) In a few paragraphs, describe the training you did to prepare for the mathematics camp and reflect on the extent of the effectiveness of these trainings. (2) How was the mathematics camp training similar and different to your previous teacher education experiences? (3) In a few paragraphs, describe the general mathematics camp setting and exactly what you did and observed. (4) What mathematics content and activities did you specifically see the students doing during the math camp? Comment on the degree to which they were involved, if they were on task, the types of problems they solved etc. (5) What did you specifically see the mathematics camp volunteers doing during the activities? Comment on the degree to which the activity was explicit instruction as well as the amount of time given to students to think and act on mathematics tasks. Explain how the mathematics camp volunteers leading the activities structured the learning and how this relates to classroom management. (6) Describe three aspects of the mathematics camp that made it a positive experience for the students and why you believe these aspects led to a positive experience. (7) Reflect on your experience of the mathematics camp instructional environment. What did you gain from the experience of 
participating as a volunteer in the mathematics camp? How has this experience helped you prepare to be a teacher of mathematics?

\section{Data Collection}

Classroom field note observations, videotape, and document collection were used for the data collection in addition to the reflections. On the one hand, two researchers participated in all of the activities including math camp training and two math camps (See Table 1). They collected field note observations of both Chinese and American prospective mathematics teachers' performance and middle school students' performance in the two days of math camps. They also captured many small videos and photos of students' work on site. Additionally, the first researcher videotaped the whole day's activity for the second math camp in School B by using a camera.

Teachers' growth equals experience plus reflection. In order to promote the growth of both Chinese and American prospective mathematics teachers, the researchers required each prospective teacher who participated in these math camps to write a reflection report for the whole communication activity about teaching by answering the question prompts (see instruments section). Thirty reflection reports were collected, 18 of them came from Chinese prospective mathematics teachers and 12 of them came from American prospective mathematics teachers.

\section{Data Analysis}

By the researchers' on-site field note observations of both math camps in School A and School B and watching the videotapes for the whole day's activity for the second math camp in School B again and again, the researchers refined the features of math camps. The text from prospective mathematics teachers' reflection reports were analyzed using a constant comparative method (Corbin \& Strauss, 2008) whereby coding and analyzing occurred simultaneously (Taylor \& Bogdan, 1998). For this part of the analysis, researchers used a computer assisted qualitative data analysis software, Nvivo 11. Two hundred and sixty-nine codes were generated. The second round of analysis of these codes identified some different perspectives between Chinese and American prospective mathematics teachers. For example, American prospective mathematics teachers paid much more attention to the representational form of the problems and Chinese prospective mathematics teachers paid much more attention to the essential content of the problems, which may reflect their differences on teachers' noticing of classroom teaching (Sherin et al., 2011).

\section{Results}

\section{The Strengths of Math Camps}

The math camps had several distinct strengths from analysis of the 
teacher educators' classroom field note observations, analyzing video lessons and prospective teachers' reflection reports. The analysis resulted in identifying three major themes:(1) advocating learning with enjoyment; (2) encouraging team cooperation, and (3) promoting multicultural teaching.

Advocating learning with enjoyment. Learning with enjoyment was one of the distinct strengths of these math camps jointly carried out by Chinese and American prospective mathematics teachers. How can they attract students' interest in learning and achieve the purpose of learning mathematics with enjoyment? Singing and dancing, a teaching strategy that is deemed as having nothing to do with the mathematics classroom from the point of view of most Chinese teachers, was successfully used in the teaching of these math camps. These dances closed the gap between prospective teachers and middle school students in math camp. They also aroused the enthusiasm of students' participation in activities.

Singing and dancing was very important from the American prospective mathematics teachers' perspective. For example, An American prospective teacher CC wrote:

The math camp dances are one of the biggest ways that we create a positive environment throughout the camp. By doing these, we are able to create an identity within our team and give our campers a way to take a break between activities that gets their blood pumping (02/2017).

Another American prospective teacher NE wrote: "Prospective teachers from American A University and Chinese B University were very animated and enthusiastic that enabled the [middle school] students to be the same way (02/2017)." American prospective teacher WC wrote:

A final positive aspect of these math camps in China would be that they can change the focus of students from rote mathematics into mathematics being a subject to be enjoyed in many different ways. An important focus of math camp is to ensure that students have fun and see mathematics as enjoyable and not just a class they have to study for, but something they can enjoy (02/2017).

Beliefs about learning with enjoyment in these math camps also gave Chinese prospective mathematics teachers a deep impression. For example, when talking about the positive experiences that math camps brought to the middle school students, Chinese prospective teacher ZY wrote: "Students felt more happy than tired in math camps (02/2017)." 
Encouraging team cooperation. Encouraging team cooperation was another important strength of these math camps jointly carried out by Chinese and American prospective mathematics teachers. The spirit of team cooperation of math camps was embodied not only in the cooperation among campers, but also in cooperation among Chinese and American prospective mathematics teachers and their leaders. This cooperation was all around: from the preparation of materials to personnel scheduling, from the design of tasks to work arrangement, from the translation of language to classroom management, from the implementation of instruction to the writing of reflective reports. Each stage embodied the effects of cooperation of the Chinese and American mathematics teaching groups. The successful implementation of math camps brought deep influence on the beliefs of both Chinese and American prospective mathematics teachers.

From the point of view of American prospective teachers, the gold standard for celebrating the victor of math camp was the best team for cooperation rather than the strongest team for problem solving. The spirit of team cooperation advocated in these math camps also gave Chinese prospective mathematics teachers a deep impression. Throughout all the stages of math camp training and the processes of math camp, they expressed appreciation for this spirit. For example, when talking about the effectiveness of math camp training, Chinese prospective teacher HK wrote: "The math camp training taught us the spirits of team cooperation and personality of bravery (02/2017)". When talking about the differences between math camps and previous teacher education experiences, Chinese prospective teacher WX wrote: "I feel each of us participated in lesson preparation for math camps. At the end of each math camp day, we sat down in a circle and expressed our own opinions on the whole activities (02/2017)". When talking about the positive experiences that math camps brought to the middle school students, Chinese prospective teacher TL wrote:

The activities of math camps were organized as teams. Each stage advocated team cooperation. We also appraised for excellent teamwork, which made middle school students realize the importance of team cooperation in math camp. So, they tried their best to cooperate with each other in math camp, which enhanced the spirit of team cooperation (02/2017).

When talking about the personal gains from participation in math camps, Chinese prospective teacher LY wrote: "These math camps advocated the spirit of team cooperation. I think it can be applied to my future teaching (02/2017)." 
Promoting multicultural teaching. American prospective mathematics teachers widely realized that the experience of math camps would be helpful to teach in a multicultural classroom in the future. For example, American prospective mathematics teacher PJ wrote: "These two camps were also very different because they were held in a different country that speaks a different language and is not necessarily used to this type of mathematics learning. It provided many challenges to work through and that is what made it different (02/2017)." When talking about the personal gains from participation in math camps, American prospective teacher NT wrote:

This will help me in the classroom because not all my students will be white males like me. I will need to adapt my classroom to potential English language learners and other ethnicities. It was a great experience for me and the other students who had this opportunity. I will never forget this experience $(02 / 2017)$.

\section{The Weaknesses of Math Camps}

Although both Chinese and American prospective mathematics teachers agreed with the strengths of math camps, they showed different teacher noticing of the weaknesses of math camps. From the point of view of the Chinese prospective mathematics teachers, the following aspects of math camp needed to be improved: making of a reward system, management of classroom teaching, analysis of students' mathematical knowledge prior to camp, arrangement of time for teaching, treatment of classroom summary, and difficulty levels of mathematical problems. For example, when talking about the making of a reward system, Chinese prospective mathematics teacher GJJ wrote: "We should make a better reward system. A quantitative standard should be made to decide how to reward for students' good performance (02/2017)." When talking about management of classroom teaching, Chinese prospective mathematics teacher TL wrote: "A team consists of about six students is more suitable. In this case, each student in the team can realize the importance of himself or herself. So, they may actively participate in math camp (02/2017)." When talking about analysis of students' mathematical knowledge prior to math camp, she pointed out that a survey should be done before each math camp so that mathematical tasks could be designed to align with students' realities. TL also talked about arrangement of time for teaching. She wrote: "We should cut down some activities or increase the time for some activities so that students can have enough time to explore, to think, to experience and to look back (02/2017)." When talking about the treatment of classroom summary, Chinese prospective mathematics teacher LQP wrote: "we should leave several minutes for students after each mathematical task so that team members can introduce the difficulties which they met during problem solving. In a word, reflection and summary for each mathematical task should be strengthened (02/2017)." Chinese prospective mathematics teacher APL wrote: "The difficulty levels of 
mathematical problems is not accordance with middle school students' realities. We should prepare matched mathematical problems for corresponding grade levels of students $(02 / 2017)$."

However, from the point of view of American prospective mathematics teachers, the following aspects of math camps also needed to be improved: well established communication with middle schools ahead of time, management of classroom teaching, and conquering language barriers. For example, American prospective mathematics teacher LA wrote: "One aspect that could have been better at both camps was better preparation and communication with the school, so we know what we have available when it comes to space and rooms to use (02/2017)." American prospective mathematics teacher LL wrote: "The first aspect that could be better about math camp is making a clearer pattern of rotation for the stations (02/2017)." When talking about language barriers, American prospective mathematics teacher SR wrote: "Make sure the English is not too difficult...Eliminating the question or even putting in their language are some possible solutions (02/2017)."

\section{Middle Zone of Chinese and American Mathematics Teaching}

After making a comprehensive survey on the process of the math camp experiences and reflections of the Chinese and the American prospective mathematics teachers, it was found that Chinese prospective teachers paid great attention to spirit of team cooperation and beliefs about learning with enjoinment advocated in these math camps. It is familiar for Chinese prospective teachers that teaching should foster the spirit of team cooperation. However, it is not easy to do so in classroom teaching. In their previous educational experiences, Chinese prospective teachers have few opportunities to do so. Math camps gave them vivid experiences. So, the spirit of team cooperation received wider attention from Chinese prospective teachers. In contrast, American prospective teachers mentioned only a little of spirit of team cooperation. This doesn't mean that they don't care about team cooperation. On the contrary, from their perspective it simply stands to reason that fostering a spirit of team cooperation in classroom teaching is an important focus. Team cooperation is more common in their educational experiences. They don't have to pay as much attention to it. American prospective teachers paid much more attention to the elements of learning with enjoyment and engaging much energy through interweaving singing and dancing with time of mathematical problem solving. They hoped to activate students' vitality and energy by singing and dancing, so that students can experience the fun of learning. Of course, Chinese prospective teachers also paid attention to this point.

However, Chinese prospective teachers' noticing of classroom teaching are quite different from that of American prospective teachers when it turned to analysis of students' learning basis, arrangement of time for teaching, treatment of classroom summary, and level of difficulty of mathematical problems. These factors were more essential for classroom teaching from the perspective of 
Chinese prospective teachers, which also got special attention in their previous educational experience. In contrast, almost none of the American prospective teachers mentioned these factors.

It seemed that Chinese prospective mathematics teachers paid much more attention to the essential content of classroom teaching; however, American prospective mathematics teachers paid much more attention to the representational form of classroom teaching. If "paying attention to essential content" and "paying attention to representational form" are regarded as two poles of Chinese and American mathematics teaching, then, the middle zone of Chinese and American mathematics teaching may include strengthening adherence to teaching both essential content and representational form. Only paying attention to the representational form and not paying attention to the essential content would allow for loss of learning from the students and this is of course unacceptable. At the same time, only paying attention to the essential content and not paying attention to the representational form may cause some students to become disinterested in mathematics and also result in a loss of learning.

\section{Discussion and Conclusions}

This study set out to search for the middle zone of Chinese and American mathematics teaching by carrying out teaching activities through math camps. The findings of this study suggest that Chinese prospective mathematics teachers appreciated their American counterparts' effort to help the students to learn with enjoyment and work in a team. However, they paid more attention to the essential content of classroom teaching in math camps. American prospective mathematics teachers cherished the opportunity to teach in a multicultural classroom. However, they paid more attention to the representation form of classroom teaching.

From the point of view of Chinese prospective mathematics teachers, these math camps got middle school students learning with enjoyment in the way of teamwork. It is helpful to enhance middle school students' interest and confidence in mathematics learning, improve prospective mathematics teachers' classroom teaching and management, and promote communication about teaching between Chinese and American mathematics teachers.

The following aspects of math camps need to be improved: making of a reward system, management of classroom teaching, analysis of students' mathematical knowledge prior to math camp, arrangement of time for teaching, treatment of classroom summary, and difficulty levels of mathematical problems. From the point of view of American prospective mathematics teachers, these math camps got middle school students learning with enjoyment and being full of energy by singing and dancing interwoven with times of mathematical problem solving. It was helpful to enhance middle school students' interest and confidence in mathematics learning, strengthen American 
prospective teachers' understanding to Chinese mathematics teaching culture, and improve American prospective teachers' ability of teaching in a multicultural classroom.

The findings suggest the following aspects of the math camps need to be improved: well established communication with middle schools ahead of time, management of classroom teaching, and conquering language barriers. By considering American prospective mathematics teachers' teaching intentions and comparing the differences between Chinese and American prospective mathematics teachers' noticing of classroom teaching in math camps, it was found that Chinese prospective mathematics teachers paid much more attention to the essential content of classroom teaching, and American prospective mathematics teachers paid much more attention to the representational form of classroom teaching. We inferred that the middle zone of Chinese and American mathematics teaching might include strengthening adherence to teaching both essential content and representational form.

In Chinese mathematics teaching culture, the essential content is much more important than the representational form. Just as two well-known Chinese mathematics educators, Chen Zhongmu and Song Naiqing, advocated: "preoccupation of the form should be reduced, and the essence should be highlighted in teaching" (Chen \& Song, 1993, p.4).

Chinese mathematics teachers believed that an effective teacher could correctly predict students' learning difficulties (Cai \& Wang, 2010), which was in accordance with the Chinese prospective mathematics teachers' concerns on the analysis of the students' learning basis in the math camps. On the other hand, the American mathematics teachers believed that an effective teacher could manage the classroom effectively, which was in accordance with American prospective mathematics teachers' concerns on management of classroom teaching in math camps.

Chinese prospective mathematics teachers also paid more attention to the difficulty levels of mathematical problems in math camps, which also reflected the typical Chinese teachers' concerns. For example, Huang et al. (2016) found that Chinese teachers preferred to give tasks that required higher cognitive demand of students than American teachers (Huang et al., 2016). In order to promote students' thinking ability, Chinese teachers paid more attention to different levels of problems, however, American teachers paid more attention to learning via team cooperation (An, Kulm, \& Wu, 2007).

One of the limitations of this study was the small sample of both Chinese and American prospective mathematics teachers, however, the results showed that prospective mathematics teachers' noticing of classroom teaching in math camps are typical to a certain extent. This study suggests that the middle zone of Chinese and American mathematics teaching may include strengthening adherence to teaching both essential content and representational form. More research studies need to be done to explore the middle zone of Chinese and American mathematics teaching. During the process of searching for the middle 
zone, China and the U.S. should integrate their counterparts' orientation for teaching into their practices based on their own culture, which may promote development of mathematics education in both countries.

\section{References}

An, S. (2004). The middle path in math instruction: Solutions for improving math education. Lanham, MD: Rowman \& Littlefield Publishing Group.

An S., Kulm G., \& Wu Z., (2007). The impact of cultural differences on middle school mathematics teachers' beliefs in the U.S. and China(pp. 449-464). In F. Leung, K. Graf, \& F. Lopez-Real (Eds.), Mathematics education in different cultural traditions: A comparative study of East Asia and the West. New York, NY: Springer.

Berliner, D. C. (2001). Learning about and learning from expert teachers. International Journal of Educational Research, 35, 463-482.

Cai, J. (2005). U.S. and Chinese teachers' constructing, knowing, and evaluating representations to teach mathematics. Mathematical Thinking and Learning, 7(2), 135-169.

Cai, J., Ding, M., \& Wang, T. (2014). How do exemplary Chinese and U.S. mathematics teachers view instructional coherence? Educational Studies in Mathematics, 85(2), 265-280.

Cai, J., \& Wang, T. (2010). Conceptions of effective mathematics teaching within a cultural context: Perspectives of teachers from China and the United States. Journal of Mathematics Teacher Education, 13(3), 265-287.

Carter, K, Cushing, K, Sabers, D., Stein, P., \& Berliner, D. (1988). Expertnovice differences in perceiving and processing visual classroom information. Journal of Teacher Education, 39(3), 25-31.

Chen, Z., \& Song, N. (1993). Preoccupation of the form should be reduced, and the essence should be highlighted in teaching [in Chinese]. Journal of Mathematics Education, 2(2), 4-9.

Corbin, J., \& Strauss, A. (2008). Basics of qualitative research: Techniques and procedures for developing grounded theory ( $3 \mathrm{rd}$ ed.). Thousand Oaks, CA: Sage.

Gu, 1., Yi, 1., \& Nie, B. (2003). Searching for the middle zone: Big trends of international mathematics reform [in Chinese]. Shanghai,China: Shanghai Education Press.

Huang, R., Barlow, T., \& Prince, K. (2016). The same tasks, different learning opportunities: An analysis of two exemplary lessons in China and the U.S. from a perspective of variation. Journal of Mathematical Behavior, 4l(1),141-158.

Huang, R., \& Cai, J. (2011). Pedagogical representations to teach linear relations in Chinese and U.S. classrooms: Parallel or hierarchical? Journal of Mathematical Behavior, 30(2),149-165. 
Huang, R., \& Li, Y. (2012). What matters most: A comparison of expert and novice teachers' noticing of mathematics classroom events. School Science \& Mathematics, 112(7), 420-432.

Huang, R., \& Li, Y. (2017). Teaching and learning mathematics through variation: Confucian heritage meets Western theories. Rotterdam, The Netherlands: Sense Publisher.

Ma, L. (1999). Knowing and teaching elementary mathematics: Teachers' understanding of fundamental mathematics in China and the United States. Mahwah NJ: Erlbaum.

Sabers, D. S., Cushing, K. S., \& Berliner, D. C. (1991). Differences among teachers in a task characterized by simultaneity, multidimensionality, and immediacy. American Educational Research Journal, 28, 63-88.

Santagata, R. (2011). From teacher noticing to a framework for analyzing and improving classroom lessons (pp. 152-168). In M. Sherin, V. Jacobs, R. Philipps (Eds.), Mathematics teacher noticing: Seeing through teachers' eyes. New York, NY: Routledge.

Schack, E., Fisher, M., \& Wilhelm, J. (2017). Teacher Noticing: Bridging and Broadening Perspectives, Contexts, and Frameworks. Dordrecht, The Netherlands: Springer Scientific Publishers.

Schleppenbach, M., Flevares, L., Sims, L., \& Perry, M. (2007). Teachers' responses to student mistakes in Chinese and U.S. mathematics classrooms. The Elementary School Journal, 108(2), 131-147.

Schleppenbach, M., Perry, M., Miller, K., Sims, L., \& Fang, G. (2007). The answer is only the beginning: Extended discourse in Chinese and U.S. mathematics classrooms. Journal of Educational Psychology, 99(2), 380396.

Sherin, M., \& Han, S. (2004). Teacher learning in the context of a video club. Teaching and Teacher Education, 20, 163-183.

Sherin, M., Jacobs, V., Philipps, R. (2011). Mathematics teacher noticing: Seeing through teachers' eyes. New York: Routledge.

Sherin, M., \& van Es, E. (2005). Using video to support teachers' ability to notice classroom interactions. Journal of Technology and Teacher Education,13, 475-491.

Star, J. R., \& Strickland, S. K. (2008). Learning to observe: Using video to improve preservice mathematics teachers' ability to notice. Journal of Mathematics Teacher Education, 11, 107-125.

Taylor, S. J., \& Bogdan, R. (1998). Introduction to qualitative research methods: A guidebook and resource. (3rd ed.). New York: Wiley.

van Es, E., \& Sherin, M. (2008). Mathematics teachers "learning to notice" in the context of a video club. Teaching and Teacher Education, 24, 244-276.

Yuan, Z., \& Ricks, T. (2011). Juxtaposing Chinese and American mathematics teachers' classroom based on mathematical problems: A case of geometric probability model [in Chinese]. Fujian Education (B), 11, 34-36. 
Author Note: This research was supported by Hunan Province Department of Education, P. R. China under Grant No.2016-122 titled Research and Practices on Reform of Curriculum System of Mathematics Teacher Education and Teaching Content. It was also supported by Hunan Normal University under Grant No. 2018-14-16 titled Research on Development Model of All-in-one Integration of Bachelor's and Masters' Future Distinguished Secondary School Mathematics Teachers. The opinions, findings, and conclusions expressed in this material are those of the authors and do not necessarily reflect the views of the funding agencies. The authors would like to thank the anonymous reviewers for their detailed and valuable comments, which helped greatly the improvement of this manuscript.

\section{Authors:}

Zhiqiang Yuan, Ph.D.

Hunan Normal University, Changsha, Hunan, China;

Email:zhqyuan@hunnu.edu.cn

Gabriel Matney, Ph.D.

Bowling Green State University, Bowling Green, Ohio, U.S.A.

Email: gmatney@bgsu.edu 